\title{
Induction of meiosis by embryonic gonadal somatic cells differentiated from pluripotent stem cells
}

\author{
Haiying Wang ${ }^{1,2}$, Linlin Liu ${ }^{1,2}$, Chang Liu ${ }^{1,2}$, Lingling Wang ${ }^{1,2}$, Jiyu Chen ${ }^{1,2}$, Huasong Wang ${ }^{4}$, Dai Heng H,2 $^{1,}$ \\ Ming Zeng ${ }^{5}$, Chun Liu ${ }^{1,2}$, Zhongcheng Zhou ${ }^{6}$, Xiaoying Ye ${ }^{1,2}$, Yajuan Wan ${ }^{1}$, Huiyu Li ${ }^{1,2}$ and Lin Liu $u^{1,2,3^{*}}$ (D)
}

\begin{abstract}
Background: Depletion of oocytes leads to ovarian aging-associated infertility, endocrine disruption and related diseases. Excitingly, unlimited oocytes can be generated by differentiation of primordial germ cell like cells (PGCLCs) from pluripotent stem cells. Nevertheless, development of oocytes and follicles from PGCLCs relies on developmentally matched gonadal somatic cells, only available from E12.5 embryos in mice. It is therefore imperative to achieve an in vitro source of E12.5 gonadal somatic cells.
\end{abstract}

Methods: We explored to identify small molecules, which can induce female embryonic stem cells (ESCs) into gonadal somatic cell like cells.

Results: Using RNA-sequencing, we identified signaling pathways highly upregulated in E12.5_gonadal somatic cells (E12.5_GSCs). Through searching for the activators of these pathways, we identified small-molecule compounds Vitamin C (Vc) and AM580 in combination (V580) for inducing differentiation of female embryonic stem cells (ESCs) into E12.5_GSC-like cells (E12.5_GSCLCs). After V580 treatment for 6 days and sorted by a surface marker CD63, the cell population yielded a transcriptome profile similar to that of E12.5_GSCS, which promoted meiosis progression and folliculogenesis of primordial germ cells. This approach will contribute to the study of germ cell and follicle development and oocyte production and have implications in potentially treating female infertility.

Conclusion: ESCs can be induced into embryonic gonadal somatic cell like cells by small molecules.

Keywords: ESCs, GSCLCs, Meiosis, Small molecules, Female infertility

\section{Introduction}

With the increasing pressure of social competition, many women choose to postpone their childbearing age. Coupled with the influence of diet and environmental factors, the phenomenon of infertility caused by ovarian aging has increased significantly [1-3]. In addition, ovarian aging can lead to early menopause and related chronic diseases, such as coronary heart disease, osteoporosis,

\footnotetext{
*Correspondence: liulin@nankai.edu.cn

1 State Key Laboratory of Medicinal Chemical Biology, Nankai University, Tianjin 300071, China

Full list of author information is available at the end of the article
}

and endocrine disorders, which seriously affect female reproduction and physical and mental health [4-7]. Depletion of oocyte and follicle reserve in vivo makes direct contribution to ovarian aging. Hence, extensive efforts have been made over the last decades to generate oocytes in vitro, from other source, such as from pluripotent stem cells.

Close interactions between germ cells and somatic cells are essential for ovarian development and function [810], and can control germ cell proliferation, meiotic entry and arrest as well as formation of the primordial follicle pool [11, 12]. Embryonic primordial germ cells (PGCs) original author(s) and the source, provide a link to the Creative Commons licence, and indicate if changes were made. The images or other third party material in this article are included in the article's Creative Commons licence, unless indicated otherwise in a credit line to the material. If material is not included in the article's Creative Commons licence and your intended use is not permitted by statutory regulation or exceeds the permitted use, you will need to obtain permission directly from the copyright holder. To view a copy of this licence, visit http://creativecommons.org/licenses/by/4.0/. The Creative Commons Public Domain Dedication waiver (http://creativeco mmons.org/publicdomain/zero/1.0/) applies to the data made available in this article, unless otherwise stated in a credit line to the data. 
undergo migration and proliferation, followed by meiosis, which is arrested at diakinesis during prophase I prior to birth [13-17]. Meiosis continues after puberty, and oocytes develop with granulosa cells during folliculogenesis, giving rise to mature oocytes for reproduction. As the number of germ cells is set at birth in most mammalian species [18-21], current evidence does not support neo-folliculogenesis after the ovarian reserve is determined $[22,23]$. Meanwhile, depletion of a limited follicle reserve, together with some uncontrollable factors, such as age, food, and the haze environment, lead to a series of diseases, including endocrine disorders and infertility $[1,2]$. Remarkably, oocyte-like cells [24] and PGC-like cells (PGCLCs) [25-29] have been consistently obtained from pluripotent stem cells. Furthermore, PGCLCs and E12.5 PGCs require reconstitution with E12.5_GSCs to enter meiosis and folliculogenesis for production of functional oocytes and, consequently, offspring $[27,29]$. This approach holds great promise for the treatment of infertility as well as for restoration of ovarian endocrine function as an alternative to feasible, yet risky methods such as hormone replacement therapy [30-32]. Furthermore, reconstitution of the entire process of gametogenesis has been achieved in vitro, thus, providing a platform for analyzing the mechanistic details of oogenesis [33].

To fulfill the potential of PGCLCs in vitro, their necessary interaction with developmentally matched gonadal somatic cells must be ensured for normal folliculogenesis [34-37]. However, successful PGCs development and maturation experiments currently require embryo destruction to obtain matched somatic cells. Meanwhile, it has been suggested that only E12.5_GSCs can support maturation of nascent PGCs or PGCLCs into mature oocytes $[27,29,38,39]$. They aggregated PGCs or PGCLCs with E12.5 GSCs to form reconstituted ovaries and transplanted them into ovarian bursa or kidney capsules [38-40]. PGCs in the reconstituted ovaries matured into germinal vesicle-stage oocytes, which then contributed to fertility following in vitro maturation and fertilization [29, 33]. However, to construct a successful platform for elucidating the molecular mechanisms underlying meiosis and oocyte production, developmentally matched gonadal somatic cells are indispensable. These cells have only been obtained from E12.5 female gonads [33], until a recent breakthrough [41]. Moreover, the embryo destruction required for obtaining these cells is not feasible in humans. Therefore, an alternative approach for the generation of these cells in vitro is imperative [33]. Compared with genetic manipulation and difficult-to-manufacture biologics, small molecules offer advantages, including cell permeability, cost-effectiveness, no immunogenicity, simpler synthesis, batchto-batch consistency, and preservation [42]. In addition, their regulatory effects on protein function are reversible and can be fine-tuned by varying their concentrations [43]. Hence, we sought to identify small-molecule compounds that can stimulate the differentiation of ESCs into E12.5_GSCLCs. Our approach may facilitate further indepth study of oocyte production.

\section{Methods \\ Mouse embryonic fibroblasts (MEF) isolation and cell culture}

All the animal experiments were performed following the ethical guidelines approved by Tianjin Animal Management Committee. MEF cells were derived from E13.5 embryos isolated from $\mathrm{B} 6 \mathrm{C} 3 \mathrm{~F} 1$ mice via cesarean section and washed in phosphate-buffered saline (PBS). Heads and visceral tissues were removed, and the remaining tissue was washed in PBS, submerged in $0.25 \%$ trypsinEDTA (0.25\% TE, Invitrogen), and incubated at $37^{\circ} \mathrm{C}$ for $10 \mathrm{~min}$. The tissue was pipetted repeatedly to aid dissociation, washed, and plated in MEF medium, Dulbecco's modified eagle's medium (DMEM, Invitrogen) supplemented with $10 \%$ fetal bovine serum (FBS, Hyclone), $1 \mathrm{mM}$ L-glutamine (Invitrogen), 1\% nonessential amino acid stock (NEAA, Sigma), penicillin $(100 \mathrm{U} / \mathrm{mL})$, and streptomycin $(100 \mu \mathrm{g} / \mathrm{mL})$. Cells were cultured at $37{ }^{\circ} \mathrm{C}$ in $5 \% \mathrm{CO}_{2}$ with humidified air (Thermo Scientific, USA). ESC lines were established and characterized based on a previously described method [44], cultured in KnockOut DMEM supplemented with 20\% FBS (ES quality, Hyclone), $1000 \mathrm{U} / \mathrm{mL}$ leukemia inhibitory factor (LIF) (ESGRO, Chemicon), $0.1 \mathrm{mM}$ nonessential amino acids, $0.1 \mathrm{mM} \beta$-mercaptoethanol, $1 \mathrm{mM} \mathrm{L}$-glutamine, penicillin $(100 \mathrm{U} / \mathrm{mL})$, and streptomycin $(100 \mu \mathrm{g} / \mathrm{mL})$.

\section{Magnetic-activating cell sorting (MACS)}

MACS was performed according to the manufacturer's instructions (Miltenyi). Briefly, dissociated E12.5 gonadal cells were treated with $0.05 \%$ trypsin-EDTA to harvest single cells, resuspended in $80 \mu \mathrm{L}$ of MACS buffer containing $0.5 \%$ BSA and $2 \mathrm{mM}$ EDTA $(\mathrm{pH}=8.0)$, then incubated with $20 \mu \mathrm{L}$ anti-SSEA1 antibodies conjugated to magnetic beads (Miltenyi) on ice for $20 \mathrm{~min}$. Cell suspensions were washed in PBS and applied to an MS column to separate SSEA1-positive cells (PGCs) and SSEA1negative cells (E12.5_GSCs). GSCs were collected from the flow-through. The cells that remained on the column were PGCs. To ensure that PGCs do not contain E12.5 GSCs, we filtered them through the MS column thrice.

\section{RNA extraction and quantitative real-time PCR (qPCR)}

RNA was extracted from samples using RNeasy Mini Kit (Qiagen) according to manufacturer's method. $2 \mu \mathrm{g}$ RNA were reversely transcribed into cDNA using 
M-MLV reverse transcriptase (Invitrogen). Quantitative real-time PCR reactions were set up in duplicate with the Faststart Universal SYBR Green Master Mix (Roche) and run on the real-time PCR Detection System (Bio-Rad). Gapdh was served as the internal control. The primers used are listed in Additional file 1: Table S1.

\section{Induction of GSCLCs from ESCs}

Before cell induction, we prepared a 12-well culture plate coated with human plasma fibronectin (HFN, $16.7 \mathrm{mg} /$ $\mathrm{mL}$, Millipore) kept for at least $1 \mathrm{~h}$ in a $37^{\circ} \mathrm{C} \mathrm{CO}_{2}$ incubator. ESCs cultured in $2 \mathrm{i}$ + LIF (2iL) medium for at least two passages were then dissociated with $0.25 \% \mathrm{TE}$, washed, centrifuged at $1200 \mathrm{rpm}$ for $3 \mathrm{~min}$, and resuspended in ES medium without 2iL. ESCs were then cultured in a new 6-well plate for $30 \mathrm{~min}$ to remove feeders based on differences in adherence to the dish, followed by seeding at a density of $10^{5}$ cells per well in HFN-coated 12 -well plates. The differentiation medium containing the respective small-molecule compounds was changed every other day. After MACS for the removal of SSEA $1^{+}$ cells, the remaining SSEA1 ${ }^{-}$cell population was considered GSCLCs and used for aggregation.

\section{Induction of meiosis}

Induction of meiosis was achieved by aggregation of PGCs with E12.5_GSCs isolated from E12.5 female gonads, GSCLCs induced via V580_D6, ovary somatic cells isolated from 6 weeks old mice $\left(\mathrm{P}_{6 \mathrm{w}}\right)$ and MEF cells. Aggregates were cultured for four days to induce meiosis in the wells of a low-cell-binding U-bottom 96-well Lipidure-Coat plate in gonad medium, containing M199 supplemented with $10 \% \mathrm{FBS}, 1 \mathrm{mM} \mathrm{L}$-glutamine, penicillin $(100 \mathrm{U} / \mathrm{mL})$, and streptomycin $(100 \mu \mathrm{g} / \mathrm{mL}), 50 \mu \mathrm{g} / \mathrm{mL}$ $\mathrm{Vc}$ and $10 \mu \mathrm{M}$ Rocki.

\section{Aggregation of $\mathrm{P}_{6 \mathrm{w}}$ via $\mathrm{PHA}$}

As $\mathrm{P}_{6 \mathrm{w}}$ cannot perfectly aggregate with $\mathrm{PGCs}$, before adding the aggregate into a low-cell-binding U-bottom 96-well Lipidure-Coat plate, cells were resuspended in $100 \mu \mathrm{L}$ of gonad medium. After the addition of phytohemagglutinin-P (PHA), cell suspensions were incubated at $37^{\circ} \mathrm{C}$ for $10 \mathrm{~min}$. Subsequently, the suspensions were centrifuged twice at $9000 \times g$ for $1 \mathrm{~min}$ to obtain re-aggregated pellets. The re-aggregated cells were gently picked with a truncated $200 \mu \mathrm{L}$ micropipette, placed into a lowcell-binding U-bottom 96-well Lipidure-Coat plate filled with $200 \mu \mathrm{L}$ of gonad medium, and cultured at $37^{\circ} \mathrm{C}$.

\section{Immunofluorescence microscopy of rOvaries and differentiated cells}

rOvaries cultured on Transwell membranes were fixed for $1 \mathrm{~h}$ in $3.7 \%$ paraformaldehyde at $4{ }^{\circ} \mathrm{C}$, dehydrated through 30\% sucrose, and embedded in OCT (Optimal cutting temperature compound). After washing in PBS for $10 \mathrm{~min}$, sections were fixed with ice acetone for $15 \mathrm{~min}$ at room temperature, subjected to $0.1 \%$ Triton X-100 for 30 min, blocked with 3\% BSA in PBS for $2 \mathrm{~h}$ at room temperature or overnight at $4{ }^{\circ} \mathrm{C}$, and then incubated with the primary antibodies against Foxl2 (ab5096, Abcam), GFP(ab183735, Abcam), Gata4 (sc25310, Santa Cruz) or Vasa (ab13840, Abcam) overnight at $4{ }^{\circ} \mathrm{C}$, washed and incubated for $2 \mathrm{~h}$ with appropriate fluorescence-conjugated secondary antibodies (Donkey anti-goat IgG $(\mathrm{H}+\mathrm{L})$, Alexa Fluor 594, A-11058, Invitrogen; Donkey anti-Mouse IgG $(\mathrm{H}+\mathrm{L})$, Alexa Fluor 488, A-21202, Invitrogen; Donkey anti-rabbit IgG $(\mathrm{H}+\mathrm{L})$, Alexa Fluor 594, A-21207, Invitrogen; Donkey antimouse IgG $(\mathrm{H}+\mathrm{L})$, Alexa Fluor 594,A-21203, Invitrogen). Samples were washed thrice in PBS, counterstained with $0.5 \mathrm{mg} / \mathrm{mL}$ Hoechst 33342 (H1398, MP) in Vectashield (VectorLabs) mounting medium. Fluorescence was detected and imaged using Axio-Imager Z2 Fluorescence Microscope (Zeiss).

Differentiated cells were immunostained by washing twice with PBS; then fixed in freshly prepared $3.7 \%$ paraformaldehyde in PBS ( $\mathrm{pH} 7.4$ ), permeabilized in $0.1 \%$ Triton X-100 (Sigma-Aldrich, Saint Louis, MO) in blocking solution (3\% BSA in PBS) for $30 \mathrm{~min}$, and incubated in blocking solution for $2 \mathrm{~h}$. Cells were then incubated overnight at $4{ }^{\circ} \mathrm{C}$ with primary antibodies and secondary antibodies as described above. Nuclei were counterstained with $0.5 \mu \mathrm{g} / \mathrm{mL}$ Hoechst 33342 in Vectashield mounting medium. Fluorescence was imaged as previously described.

\section{Immunofluorescence microscopy of meiocyte spreads}

Surface spreading of meiocytes was prepared by a dryingdown technique and stained for synaptonemal complexes [45]. rOvaries were collected, digested in $0.05 \% \mathrm{TE}$ for $10 \mathrm{~min}$ at $37^{\circ} \mathrm{C}$. Cell suspensions were intermingled with five volumes of MEF medium, centrifuged at $1200 \mathrm{rpm}$ for $3 \mathrm{~min}$ and resuspended in $100 \mathrm{mM}$ sucrose. The cell suspension was spread onto glass slides by dipping onto a thin layer of fixative ( $1 \%$ paraformaldehyde, $0.15 \%$ Triton $\mathrm{X}-100, \mathrm{pH}=9.2$, which were maintained for at least $3 \mathrm{~h}$ in a humidified box and dried for $20 \mathrm{~min}$ at room temperature. The slides were then washed in water containing $0.4 \%$ Photo-flow (Kodak), and completely dried at room temperature. Dried slides were washed with $0.1 \%$ Triton X-100/PBS (PBST) for $10 \mathrm{~min}$, and incubated 
with Blocking solution (ADB, 3\% BSA, 2\% goat serum/ PBST) for $2 \mathrm{~h}$ at room temperature. Spreads were then incubated with anti-Sycp1 (ab15090, Abcam), anti-Sycp3 (NB300-230, Novus) antibody in ADB at $4{ }^{\circ} \mathrm{C}$ overnight, washed thrice, incubated with appropriate secondary antibodies, washed, and counterstained with $0.5 \mu \mathrm{g} / \mathrm{mL}$ Hoechst33342 in Vectashield mounting medium. Immunofluorescence was detected using an Axio-Imager Z2 Fluorescence Microscope.

\section{Western blot}

Cells were washed at least twice in PBS and lysed in NP40 lysis buffer containing PMSF and cocktails on ice for $30 \mathrm{~min}$, and then sonicated for $2 \mathrm{~min}$ at $60 \mathrm{amp}$ at $2 \mathrm{~s}$ intervals. The concentration of the protein sample was measured by bicinchoninic acid and boiled in SDS sample buffer at $95{ }^{\circ} \mathrm{C}$ for $10 \mathrm{~min}$. Next, $3 \mu \mathrm{g}$ of protein were electrophoresed using 10\% SDS-PAGE (Bio-Rad) and transferred to polyvinylidene fluoride membranes (PVDF, Millipore) using the Mini Trans-Blot system (Bio-Rad). Nonspecific binding was blocked in 5\% skim milk in TBST at room temperature for $2 \mathrm{~h}$ or $4{ }^{\circ} \mathrm{C}$ overnight. Blots were then probed with primary antibodies Foxl2 (ab246511, Abcam), Nanog (ab80892, Abcam), Oct4 (sc5279, Santa Cruz), Gata4 (sc25310, Santa Cruz), and $\beta$-actin (P30002, Abmart) served as a loading control. Immunoreactivity bands were then probed for $2 \mathrm{~h}$ at room temperature with the appropriate secondary antibodies, HRP-goat anti-rabbit IgG or HRP-goat anti-mouse $\operatorname{IgG}(\mathrm{H}+\mathrm{L})$. Protein bands were detected by Chemiluminescent HRP substrate (WBKLS0500, Millipore).

\section{Flow cytometry}

V580_D6 were digested into single cells and stained with CD63-PE (143903, BioLegend) antibody for $20 \mathrm{~min}$ at $4{ }^{\circ} \mathrm{C}$ and washed with fluorescence-activated cell sorting (FACS) buffer, centrifuged at $220 \times g$ for $3 \mathrm{~min}$, resuspended with FACS buffer, and then filtered by $70 \mu \mathrm{m}$ flow tube before sorting. Flow cytometry analysis and sorting were performed on a BD FACSAria Fusion (BD Biosciences).

\section{RNA-sequencing (RNA-Seq)}

Cells were harvested and total RNA extracted using RNeasy Mini kit (Qiagen), according to the manufacturers' instruction, including a DNAse digestion. A total amount of $3 \mu \mathrm{g}$ RNA per sample was used as input material for the RNA sample preparations. Sequencing libraries were generated using NEBNext ${ }^{\circledR}$ UltraTM RNA Library Prep Kit for Illumina ${ }^{\circledR}$ (NEB, USA) following manufacturer's recommendations and index codes were added to attribute sequences to each sample. To select $250-300$ bp
cDNA fragments, the library fragments were purified with AMPure XP system (Beckman Coulter, Beverly, USA). Then $3 \mu \mathrm{L}$ of USER Enzyme (NEB, USA) was used with size-selected, adaptor-ligated cDNA at $37{ }^{\circ} \mathrm{C}$ for $15 \mathrm{~min}$ followed by $5 \mathrm{~min}$ at $95{ }^{\circ} \mathrm{C}$. PCR was performed with Phusion High-Fidelity DNA polymerase, Universal PCR primers and index (X) Primer. PCR products were purified (AMPure XP system) and library quality was assessed on the Agilent Bioanalyzer 2100 system and the index-coded samples was performed on a cBot Cluster Generation System using TruSeq PE Cluster Kit (Illumina) according to the manufacturer's instructions. After cluster generation, the library preparations were sequenced on an Illumina Hiseq platform.

\section{Bioinformatics analysis}

The clean reads were mapped to the Mus musculus mm10 reference genome (downloaded from http:// genome.ucsc.edu/). Index of the reference genome was built using Hisat2 and paired-end clean reads were aligned to the reference genome using Hisat2 [46] with default parameters.

Reads were assigned and counted to genes using the featurecounts [47]. The resulting matrix of read counts was loaded into RStudio ( $\mathrm{R}$ version 3.4.2), and DESeq2 [48] were used to identify DEGs. The resulting $P$ values were adjusted using the Benjamini and Hochberg's approach for controlling the false discovery rate. Genes identified by DESeq2 with an adjusted $P$ value $<0.05$ were assigned as differentially expressed. GO enrichment analysis of DEGs was implemented by the clusterProfiler $\mathrm{R}$ package [49] and DAVID (https://david.ncifcrf.gov/), in which gene length bias was corrected. GO terms with corrected $P$ value $<0.05$ were considered significantly enriched by DEGs. Additionally, the KEGG database was used to identify high-level functions and pathways associated with the DEGs (http://www.genome.jp/kegg/). Bar plots were drawn using ggpubr and ggplot.

\section{Single-cell library preparation and sequencing}

A single-cell library was prepared using the $10 \times$ Genomics Chromium Single Cell $3^{\prime}$ Library and Gel Bead Kit v2 $(10 \times$ Genomics, Pleasanton, CA, USA, 120237) according to the manufacturer's instructions. To determine whether the cells obtained were viable (cell viability $>80 \%$, cell concentrations $=1000$ cells $/ \mu \mathrm{L}$ ) for downstream analysis, the cell viability was evaluated using trypan blue staining with a hemocytometer (BioRad, Hercules, CA, USA, TC20) and the cell concentration was adjusted to 1000 cells/ $\mu \mathrm{L}$ before loading to the single-cell chip. The Gel Bead in Emulsions (GEMs) were generated with the Chromium $10 \times$ Single Cell System $(10 \times$ Genomics $)$. To barcode cDNA in each cell, the cells 
were then lysed and reverse transcribed. cDNA recovery was performed using DynaBeads MyOne Silane Beads (Invitrogen, Carlsbad, CA, USA, 37002D) according to the manufacturer's instructions. cDNA libraries were then prepared using $10 \times$ Genomics Chromium Single Cell $3^{\prime}$ Library and Gel Bead Kit v2 following the manufacturer's guide and sequencing was performed with an Illumina HiSeq X Ten sequencer (Illumina, San Diego, CA, USA) with pair-end 150 bp (PE150) reads.

\section{$10 \times$ Genomics computational analysis}

The Cell Ranger software suite was obtained from $10 \times$ Genomics. Raw sequencing data was demultiplexed by Illumina bcl2fastq software to generate separate paired end read files for each sample, which were quality-checked using FastQC software. The Cell Ranger "count" script was used to align mouse fastq files to the mouse mm10 reference genome (Ensembl). The raw count matrices were imported into $\mathrm{R}$ for further processing. R studio (https://www.rstudio.com/) was used to run $\mathrm{R}$ scripts to perform hierarchical clustering and PCA. To identify distinct cell populations of the V580_D6 GSCLCs and E12.5_GSCs, cell clustering was performed using R software package Seurat 3.0 [50]. The count matrix was first normalized by library size and log transformed by Seurat. Transcriptomes with $<200$ expressed genes and lowly expressed in three cells were discarded, cells with mitochondrial genes occupying $>40 \%$ of reads were defined as low-quality cells and filtered out. Two datasets of V580_D6 GSCLCs and E12.5_GSCs [51](GSE128553) were integrated by "IntegratedData" function of Seurat according to instructions. Uniform Manifold Approximation (U-MAP) was used for visualization and clustering. The "FindConservedMarkers" function was used to identify canonical cell-type marker genes that are conserved across conditions.

\section{Statistical analysis}

Data were analyzed using ANOVA with Fisher's protected least-significant difference (PLSD) using the StatView software from SAS Institute Inc. (Cary, NC), two-tailed Student's $t$ test, or $\chi^{2}$ test or WilcoxonMann-Whitney rank sum test dependent on specific experiments. A $P$ value $<0.05$ was considered statistically significant.

\section{Results}

Transcriptome features at different stages of gonadal somatic cell development

We performed bulk RNA-sequencing (RNA-seq) of gonadal somatic cells from mice at different developmental stages (E12.5, E13.5, E16.5, and $\mathrm{P}_{6 \mathrm{w}}$ ). Principal component analysis (PCA) indicated that the two samples had better reproducibility during the same period (Additional file 1: Fig. S1A). Correlation between E12.5 and E13.5 was as high as 0.95 or 0.96 (Additional file 1: Fig. S1B). Differential expression analysis revealed more than 2000 differentially expressed genes (DEGs) between E13.5 and E12.5, approximately 6000 DEGs between E16.5 and E12.5, and nearly 8000 DEGs between $\mathrm{P}_{6 \mathrm{w}}$ and E12.5 (Additional file 1: Fig. S1C). A time-course line chart shows changes in gene expression during embryonic development (Fig. 1A). We analyzed DEGs among the developmental stages. Foxl2 was gradually upregulated during gonadal development (Additional file 1: Fig. S1D), which was also confirmed by the qPCR result (Additional file 1: Fig. S1E). Pairwise and multi-group DEG analysis of the four stages revealed that genes that were specifically and highly expressed in E12.5 were enriched for mesonephric development, response to retinoic acid (RA), and the Wnt and Hippo signaling pathways. Genes upregulated in E13.5 were enriched for oxidative phosphorylation, and those in E16.5 were enriched for the PI3K-Akt signaling pathway, whereas those upregulated in $\mathrm{P}_{6 \mathrm{w}}$ were primarily enriched for the AMPK signaling pathway and ovarian steroidogenesis (Fig. 1B). As we focused on E12.5, we analyzed Gene Ontology (GO) terms and Kyoto Encyclopedia of Genes and Genomes (KEGG) signaling pathways enriched at this stage (Fig. 1C-F), revealing characteristic expression pattern at each stage.

To further determine the gene expression landscape and dissect the cellular heterogeneity in the initiation of meiosis of female germ cells, we dissociated gonads from E12.5 and E13.5 embryos using the magnetic-activated cell sorting (MACS) and prepared somatic single-cell suspensions for smart-seq2 single-cell analysis (Fig. 2A). After filtering low-quality cells based on the number of genes and percentage of mitochondrial genes, we obtained a total of 345 GSCs (172 cells for E12.5 and 173 cells for E13.5), with the median number of genes per cell in the range 6000-8000. We next performed $t$-distributed stochastic neighbor embedding (tSNE) clustering analysis to dissect cellular heterogeneity within the somatic cell populations. After tSNE projection, five and four clusters of E12.5 and E13.5 somatic cells were separated via Seurat (Fig. 2B-E), and the pheatmap revealed marker genes of each cluster. In E12.5_GSCs, cluster 0 formed the early progenitor cell population and expressed marker, Nr2f1; cluster 1 represented pre-granulosa cells expressing Foxl2 and $B m p 2$; cluster 2 expressed the supporting cell marker Amhr2; cluster 3 expressed Bgn, a marker of interstitial cells; and cluster 4 expressed erythroid cell marker Alas. In E13.5_GSCs, cluster 0 expressed the mesothelial cell markers $L h x 9$, clusters 1 expressed the granulosa cell marker Foxl2, whereas cluster 2 expressed the fetal Leydig cell progenitor marker $T c f 21$. 
A

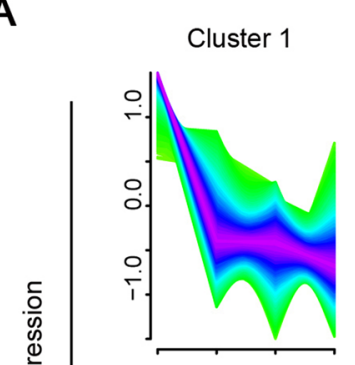

Cluster 2

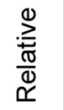

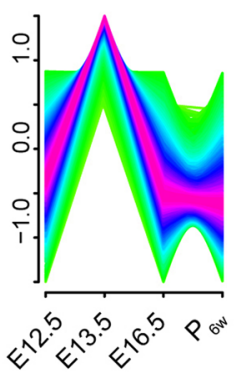

Cluster 3

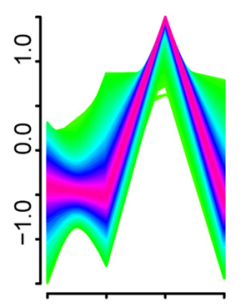

Cluster 4

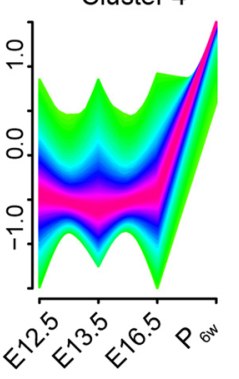

C

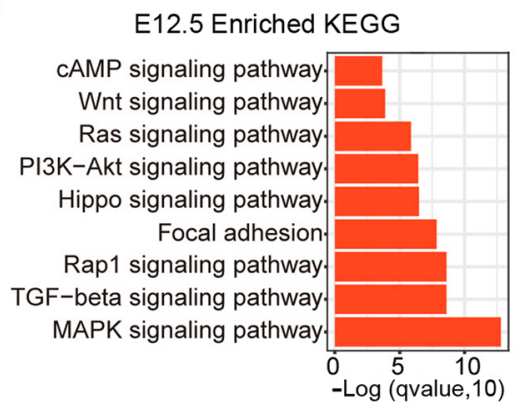

E

\section{E12.5 Enriched GO}

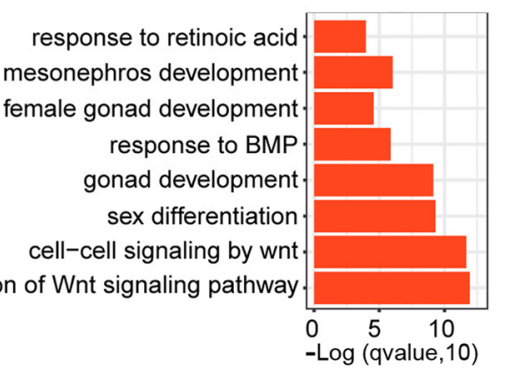

D Wnt signaling pathway

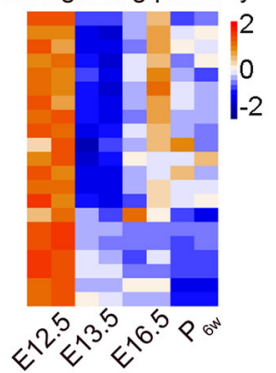

$F$ response to retinoic acid

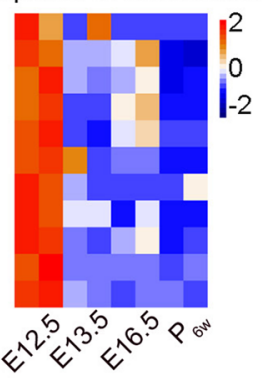

B $-2 \quad 0 \quad 2$

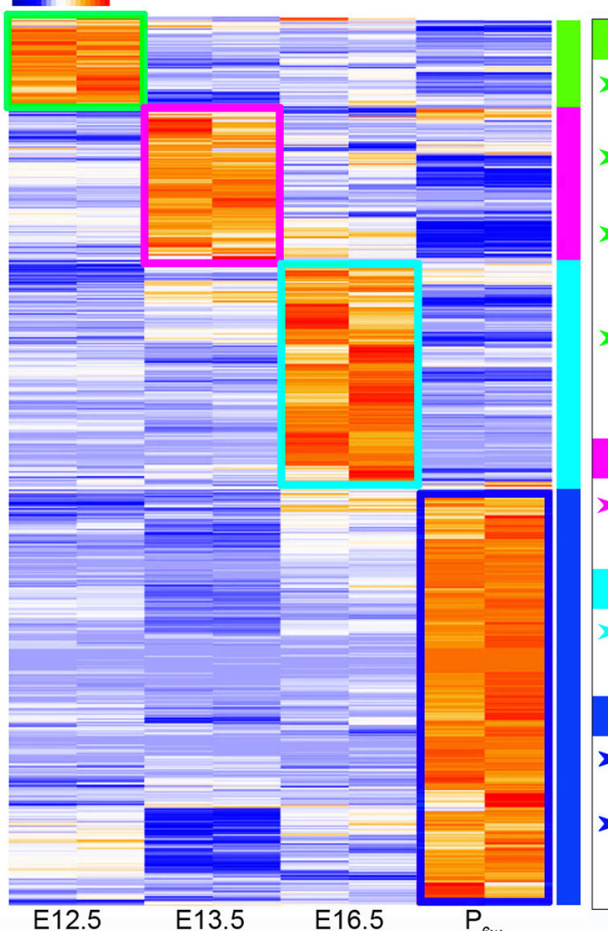

E12.5

Mesonephros development

Wt1, Bmp7,Wnt4, Wnt6, Tcf21, Lgr4,Fgfr1, Ren1,BMP4,Smad5, Gata3

$>$ Response to retinoic acid

Dkk1,Tie1,Pax2, Tesc,Halr1,Yap1,Tek,Rarb,Hoxa2,Mir3009

$>$ Wnt signaling pathway

Wnt4,Wnt6,Zfp703,Wnt5b,Mir154,Mir93,Rspo1,Ccn4,Plcb4,Lrp6,Ppp3cb,APC,

Ror1, Vangl2,Fzd4,Fzd1,Dkk1,Fzd9,Dkk2,Wif1,CCnd1,Lef1

- Hippo signaling pathway

Yap1,Tead4,Wwc1,Amot,Tead1,Ctnna3,Crb2,Fzd9,Wnt2b,Ccnd1,Wnt9a, Tead3,

Wnt6,Bmp5,Wnt11,Ccnd3,Wnt4,Ctnnb1, Lef1, Bmp4,Wnt5a, Gdf6, Id1,Afp, Gli2

\section{E13.5}

$>$ Oxidative phosphorylation

Cox8a,Ndufb4,Ndufa4,Atp5g1,Ndufa11,Uqcr10,Ndufa2,Ndufs6, Atp5k,Atp5e

E16.5

\section{- PI3K-Akt signaling pathway}

Cdk6,Osm, Foxo3, Itga4, Lamb3, Lama3, Lama2, Osmr,Lamc2,Angpt1

\section{> AMPK signaling pathway}

Prkaa2,Prkab2, Igf1r,Acacb,Fbp1,Foxo1,Pparg,Prkag2,Camkk2,Creb3/2,Scd2

$>$ Ovarian steroidogenesis

Hsd3b1,Cyp11a1,Hsd17b1,Cyp17a1,Lhcgr,Scarb1,Adcy9, Igf1r,Star,Igf1,Fshr, Cyp19a1,Ldlr,Hsd17b7,Bmp6,Cyp2j9,Bmp15,Adcy5,Cyp2j6,Gm10681,Hsd3b5

Fig. 1 Transcriptome of fetal and adult gonadal somatic cells. A Time-course line chart showing changes in gene expression during embryonic development. Cluster 1, 2, 3, and 4 represent E12.5, E13.5, E16.5, and $\mathrm{P}_{6 \mathrm{w}}$ respectively. B Enriched terms in each stage. Genes upregulated in E12.5_GSCs were clustered in mesonephric development, response to retinoic acid, Wnt signaling pathway, and Hippo signaling pathways. C KEGG analysis of enriched genes in E12.5_GSCs. Wnt, Hippo, CAMP signaling pathway were clustered in E12.5 stage. D Pheatmap showing genes enriched in Wnt signaling pathway. E GO analysis of enriched genes in E12.5_GSCs, response to retinoic acid, mesonephric development, Wnt-related signaling pathway were clustered in E12.5_GSCs. F Pheatmap showing genes enriched in response to retinoic acid 


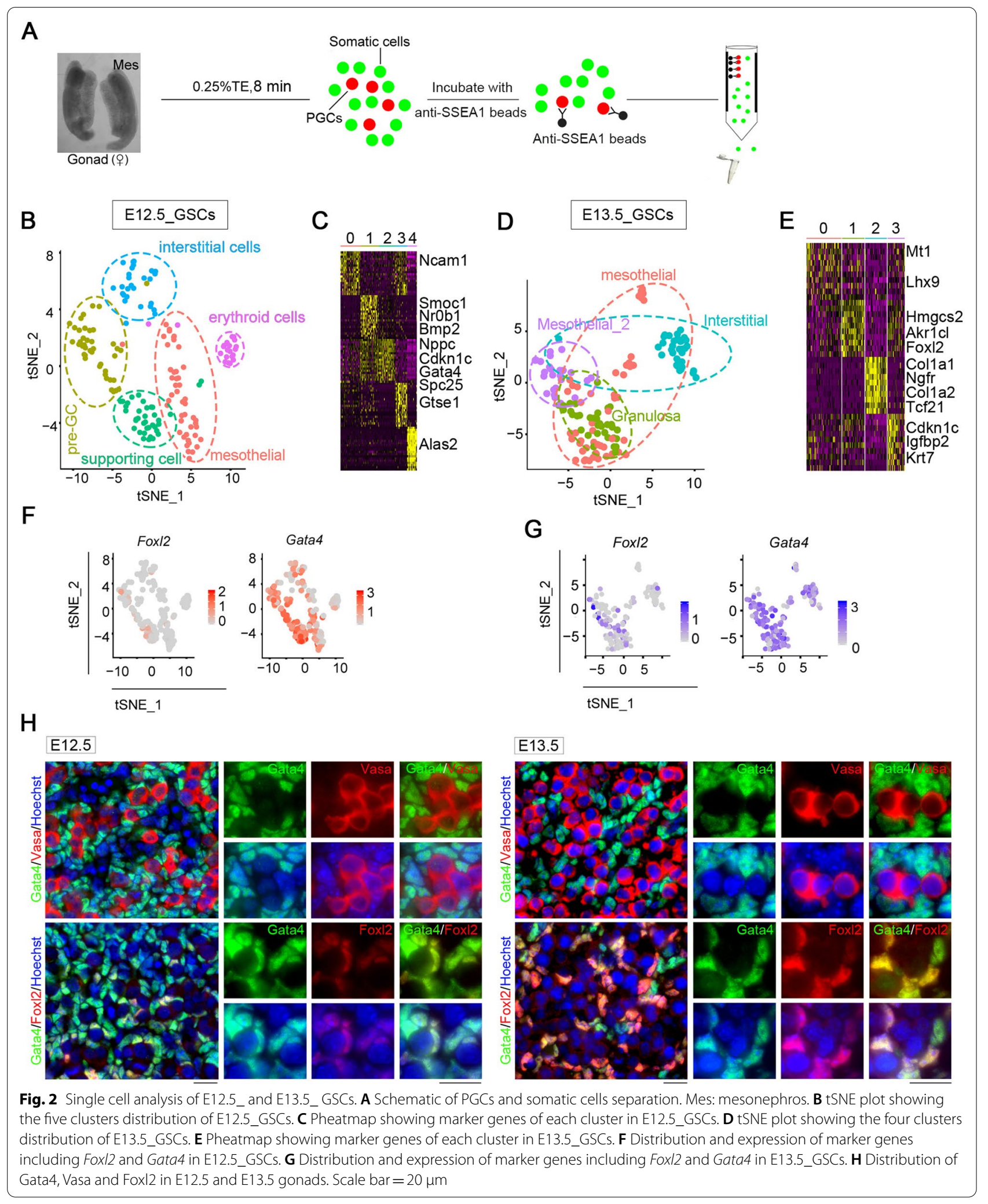




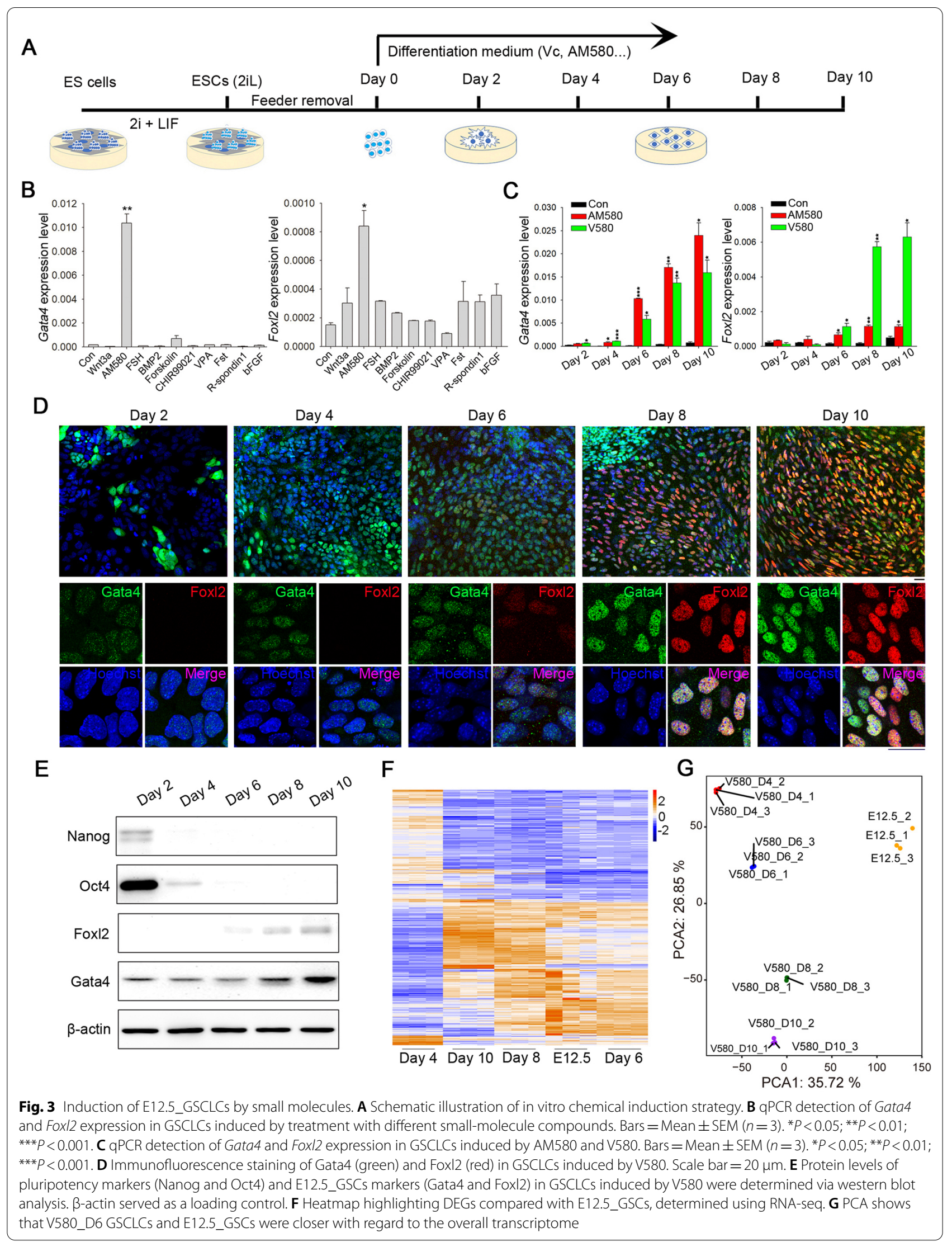


To identify somatic populations among E12.5_GSCs and E13.5_GSCs, we assessed Foxl2 and Gata4 expression, and observed that the number of Foxl2-expressing cells increased with embryonic development, whereas that of Gata4-expressing cells remained high throughout (Fig. 2F, G). To further verify the distribution of these cells in gonads, we analyzed Foxl2 expression using qPCR and performed immunofluorescence (IF) staining for Gata4, Foxl2, and Vasa, a germ cell marker (Fig. 2H). Foxl2-positive cells surrounded germ cells, with Foxl2 expression observed in Gata4-positive cells. Based on the mRNA level and protein levels, we concluded that Foxl2-positive cells originated from Gata4-positive cells, and Foxl2 was gradually upregulated during embryonic gonadal development.

\section{GSCLCs induction from ESCs by small-molecule compounds}

Based on the unique transcriptome profile of E12.5 GSCs, we sought to establish a new approach for differentiating ESCs into E12.5_GSCLCs through treatment with small-molecule compounds (Fig. 3A). The ESCs used in this study were female pluripotent stem cells expressing (or w/o) $\beta$-actin-green fluorescent protein (GFP) generated in our laboratory and stably maintained on inactivated MEF $[44,52]$. Pluripotency of these ESCs was evidenced by strong competence for generation of chimeras that gave rise to germline-competent offspring. Through the first round of small-molecule compound screening, we identified AM580 as a strong candidate, which induced upregulation of the E12.5_GSCs markers Gata4 and Foxl2 (Fig. 3B). A progressive increase in the expression of both markers was observed following AM580 treatment, whereas the expression of pluripotent genes, such as Nanog and Oct4, declined on approximately day 2 and abruptly decreased thereafter (Additional file 1: Fig. S2A, B). In addition, we used an ESC line without GFP for western blot and IF analysis, which validated the $\mathrm{qPCR}$ results (Additional file 1: Fig. S2C-E).
We next attempted to optimize our protocol through identification of additional small-molecule compounds and found that the addition of $50 \mu \mathrm{g} / \mathrm{mL} \mathrm{Vc} \mathrm{during} \mathrm{dif-}$ ferentiation facilitated somatic cell induction compared with addition of AM580 alone (Fig. 3C, D and Additional file 1: Fig. S2D), which was confirmed at the protein level using western blot (Fig. 3E), whereas IF analysis indicated that the number of Foxl2-positive cells was obviously increased (Fig. 3D). In line with the established gradual increase in Foxl2 expression during gonad development, our results indicated that Gata4 and Foxl2 were gradually upregulated throughout the induction process (Fig, $3 \mathrm{C}$ and Additional file 1: Fig. S2A). We then investigated whether the expression profile at a certain differentiation stage resembles that of E12.5_GSCs. We performed RNA-seq analysis of cell populations from different days of V580 induction. The transcriptome of V580_D6 GSCLCs was similar to that of E12.5_GSCs (Fig. 3F, G). Correlation analysis suggested that the similarity of the overall transcriptome between V580_D6 GSCLCs and E12.5_GSCs could reach 70.29\% (Additional file 1: Fig. S3A). Further, the morphology of day 6 cells was similar to that of E12.5_GSCs (Additional file 1: Fig. S3B, C). Treatment with Vc alone did not induce ESCs into GSCLCs. The morphology and marker expression levels in cells treated with $\mathrm{Vc}$ alone were similar to those of controls, with no GSCLCs observed even at day 10 (Additional file 1: Fig. S3D-G).

\section{Induction of PGC entry into meiosis by V580_D6 GSCLCs}

Abnormal meiosis can trigger infertility, premature ovarian failure, and genetic diseases $[10,53]$. This was recently confirmed by reconstituting the oocyte transcriptional network; oocytes obtained in this manner exhibited abnormal chromosomal configuration due to the absence of meiosis [54]. To determine whether V580_ D6 GSCLCs support the entry of PGCs into meiosis, we aggregated V580_D6 GSCLCs with PGCs isolated from E12.5 gonads to form aggregates (V580_D6 aggregates), which were then compared to aggregates with MEF (MEF_aggregates), $\mathrm{P}_{6 \mathrm{w}}\left(\mathrm{P}_{6 \mathrm{w}_{-}}\right.$aggregates $)$, or E12.5_GSCs

\footnotetext{
(See figure on next page.)

Fig. 4 V580_D6 GSCLCs, but not MEF and $P_{6 w^{\prime}}$ promote meiosis. A Morphology of different cell types after aggregating with PGCs. Scale bar $=50 \mu \mathrm{m}$. B The diameter of aggregates. The size of MEF_aggregates was obviously smaller, and $\mathrm{P}_{6 \mathrm{w}}$ aggregates did not form round structures even with PHA treatment, whereas Gonad_aggregates and V580_D6 aggregates did not change considerably in size. Bars $=$ Mean \pm SEM $(n=10)$. ${ }^{*} P<0.05 ;{ }^{* *} P<0.01 ;{ }^{* *} P<0.001$. C E12.5 female gonad reaggregation supports normal meiosis initiation in PGCs; V580_D6 GSCLCs can also support the normal meiosis of PGCs. In aggregates of MEF or $\mathrm{P}_{6 w}$ with PGCs, only a small amount of Sycp3 expression was observed, and the expression of Sycp1 was inhibited or completely suppressed in some cases, resulting in the inability of PGCs to proceed with normal meiosis. Scale bar $=20 \mu \mathrm{m}$. D Proportion of PGCs that can initiate meiosis in the different groups. Sycp ${ }^{+}$cells could not be detected in MEF_and $\mathrm{P}_{6 \mathrm{w}}$ aggregates. Bars $=$ Mean \pm SEM $(n=10)$. ${ }^{*} P<0.05 ;{ }^{* *} P<0.01 ;{ }^{* *} P<0.001$. E Percentage of normal synaptonemal complexes in different groups based on pachytene spread $(n=40)$. Bars = Mean \pm SEM $(n=10) .{ }^{*} P<0.05 ;{ }^{*} P<0.01 ; * * P<0.001$. F Statistics of Mlh1 foci per cell at the pachytene stage. No Mlh1 foci formed in MEF_and $P_{6 w_{-}}$aggregates. Bars = Mean \pm SEM $(n \geq 10) .{ }^{*} P<0.05 ;{ }^{* *} P<0.01 ;{ }^{* *} P<0.001$. Scale bar $=20 \mu \mathrm{m}$
} 


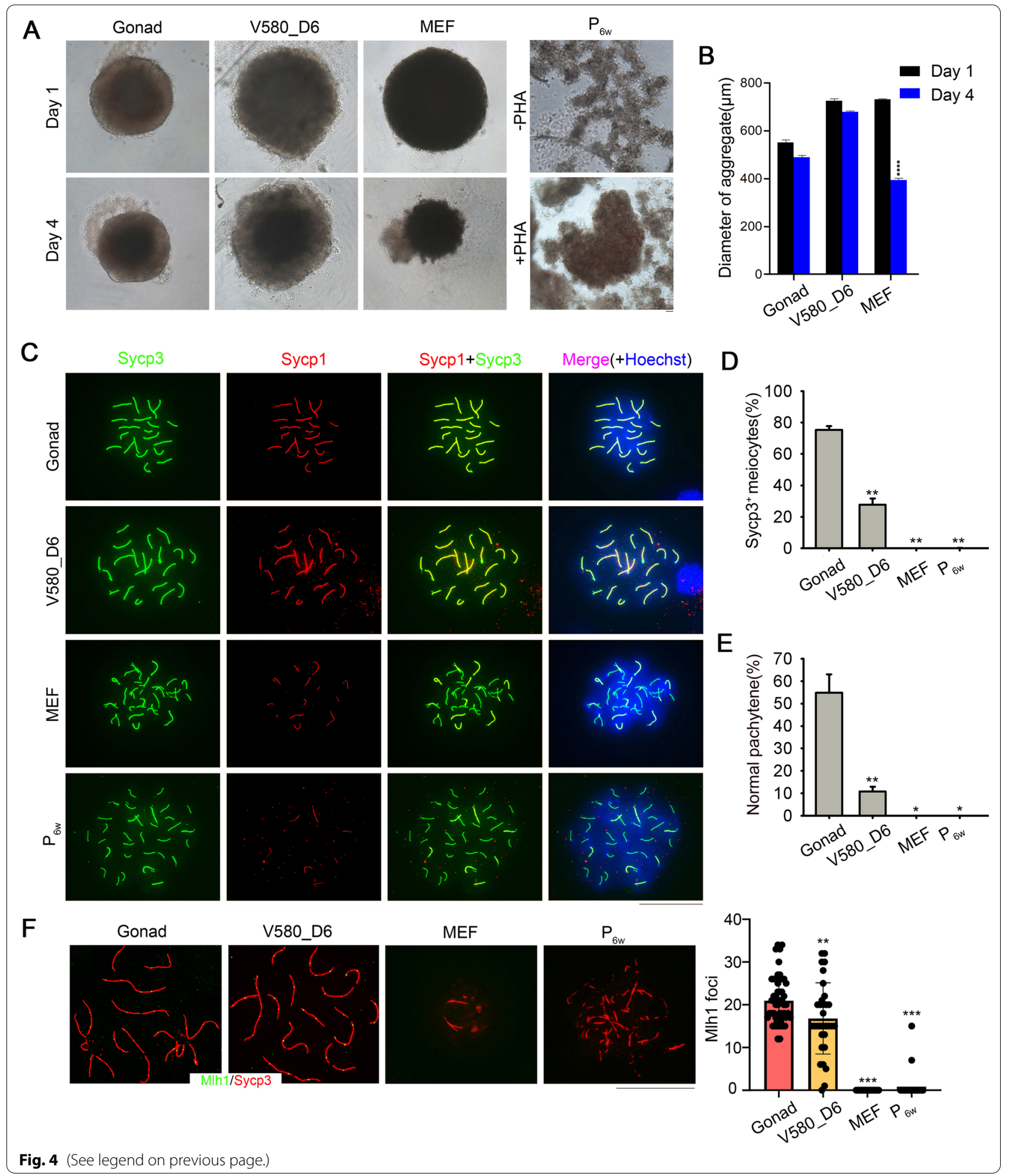

(Gonad_aggregates), as controls. The size of MEF_aggregates on day 4 was obviously smaller than day 1 , while $\mathrm{P}_{6 \mathrm{w}}$ aggregates did not form round structures even with
PHA treatment; Gonad_ and V580_D6 aggregates did not change considerably in size (Fig. 4A, B).

To determine the normality of meiosis progression in PGCs from different aggregates, we analyzed homologous 
chromosome pairing and synapsis via IF analysis of Sycp1/3 elements. Through co-staining of the Sycp1 and Sycp3 elements, normal meiosis progression was detected in V580_D6 and Gonad_ aggregates, whereas no normal pachytene meiocytes were detected in $\mathrm{MEF}_{-}$ and $\mathrm{P}_{6 \mathrm{w}_{-}}$aggregates (Fig. $4 \mathrm{C}$ ). Furthermore, Sycp3-positive $\left(\right.$ Sycp $3^{+}$) cells were not detected in $\mathrm{MEF}_{-}$and $\mathrm{P}_{6 \mathrm{~W}-}$ aggregates, thus confirming that the maturation of PGCs requires developmentally matched gonadal somatic cells. Twenty-seven percent of PGCs in V580_D6 aggregates differentiated into $\mathrm{Sycp}^{+}$meiocytes, which was lower than that observed in E12.5_aggregates (Fig. 4D). As the other control groups were highly atrophic with no normal meiocytes in pachytene, we did not determine their proportion of meiocytes. Sycp1 and Sycp3 formed the axial elements of the synaptonemal complex completed at the pachytene stage, and synaptonemal complex elements were detected in V580_D6 aggregates (Fig. 4E). In addition, the cell population induced by Vc or AM580 treatment alone did not initiate normal meiosis (Additional file 1: Fig. S4A, B). This was also confirmed by the fact that V580_D6 GSCLCs exhibited certain E12.5_GSCs' function. Mlh1, a marker of meiotic recombination, was also detected in V580_D6 aggregates (Fig. 4F). As Wnt4 and R-spondin1 play significant roles in ovary development, their absence leads to partial sex reversal [55-58]. We designed three groups to assess the function of both factors in GSCLCs' induction. First, we determined a concentration suitable for Wnt signaling pathway activation (Additional file 1: Fig. S4C) and aggregated with E12.5_ PGCs (Additional file 1: Fig. S4D). No Sycp1/Sycp3 was detected in these aggregates (Additional file 1: Fig. S4D).

To determine the pathways underlying V580_D6 GSCLCs-stimulated meiosis initiation, we compared expression profiles between V580_D6 GSCLCs and E12.5_GSCs and delineated the genes and pathways altered in V580_D6 GSCLCs. The heatmap indicated that genes related to key pathways in E12.5_GSCs exhibited a similar expression pattern as in V580_D6 GSCLCs, however, at a lower level in MEF and $\mathrm{P}_{6 \mathrm{w}}$ (Additional file 1: Fig. S5A). PCA also confirmed that V580_D6 GSCLCs resembled E12.5_GSCs (Additional file 1: Fig. S5B). KEGG analysis indicated that genes essential for E12.5_GSCs development, such as those involved in the
Wnt and Hippo signaling pathways, were upregulated in V580_D6 GSCLCs (Additional file 1: Fig. S5C). GO analysis also revealed a significant enrichment of genes for regulation of Wnt signaling, cellular response to retinoic acid, mesonephric development, and reproductive structure development (Additional file 1: Fig. S5D). Representative genes upregulated for cellular response to retinoic acid and the Hippo signaling pathway are listed (Additional file 1: Fig. S5E). In $\mathrm{P}_{6 \mathrm{w}}$, Wnt signaling, Hippo signaling pathway, mesonephric development, and gland development were upregulated to a lesser extent, whereas genes enriched for the AMPK signaling pathway, ovarian steroidogenesis, and apoptosis were highly expressed (Additional file 1: Fig. S6A-E). In MEF, the Wnt signaling pathway and steroid biosynthesis, which are indispensable in E12.5_GSCs, were not activated, whereas apoptosis-related pathways, such as the p53 signaling pathway, were activated (Additional file 1: Fig. S6F-K). To further elucidate the underlying molecular mechanisms, we performed RNA-seq analysis of the transcriptome for control GSCLCs at day 0 as well as GSCLCs treated with Vc, AM580, or V580 for $24 \mathrm{~h}$ and $48 \mathrm{~h}$. Compared with those in controls, after $24 \mathrm{~h}$ of induction, only 99 genes were upregulated and 76 were downregulated in the Vcinduced cell population; 259 were upregulated and 62 were downregulated in the AM580-induced cell population; 223 were downregulated and 410 were upregulated in the V580-induced cell population (Additional file 1: Fig. S7A, $P$ value $<0.05$, fold change $\geq 2$ ). After $48 \mathrm{~h}$ of induction, 84 genes were upregulated and 90 were downregulated in Vc-induced cells; 480 were downregulated and 1180 were upregulated in AM580-induced cells; 609 were downregulated and 1194 were upregulated in V580-induced cells (Additional file 1: Fig. S7A). KEGG analysis indicated that genes enriched for Wnt signaling, reproductive system development, hormone metabolic process, and cellular response to retinoic acid, which are essential pathways for GSCs development, were upregulated after V580 stimulation for $48 \mathrm{~h}$, which laid the foundation for their later differentiation into GSCLCs (Additional file 1: Fig. S7B). Genes enriched for canonical Wnt signaling and response to retinoic acid are listed (Additional file 1: Fig. S7C, D).

\footnotetext{
(See figure on next page.)

Fig. 5 Cell types in the induced GSCLCs revealed by single-cell RNA-seq analysis. A Left: U-map showing the distribution of E12.5_GSCs. Middle: Marker genes are indicated by color; expression gradually increases from gray to blue. Right: Proportion of each cell cluster at E12.5. B Left: U-map showing the distribution of V580_D6 GSCLCS. Middle: Marker genes are indicated by color; expression gradually increases with from gray to blue. Right: Proportion of each cell cluster among V580_D6 GSCLCs. C Left: U-map showing the distribution of CD63+_GSCLCs Middle: Marker genes are shown by the color; expression gradually increases from gray to blue. Right: Proportion of each cell cluster among CD63+_GSCLCs. D Percentage of PGCs that can initiate meiosis in the $\mathrm{CD}^{+} 3^{+}$group was slightly upregulated. E Percentage of synaptonemal complexes in the $\mathrm{CD}^{-} 3^{+}$group based on pachytene spread $(n=40)$ was significantly upregulated. Bars = Mean $\pm \operatorname{SEM}(n=10)$. ${ }^{*} P<0.05 ;{ }^{* *} P<0.01 ; * * * 0.001$
} 
A
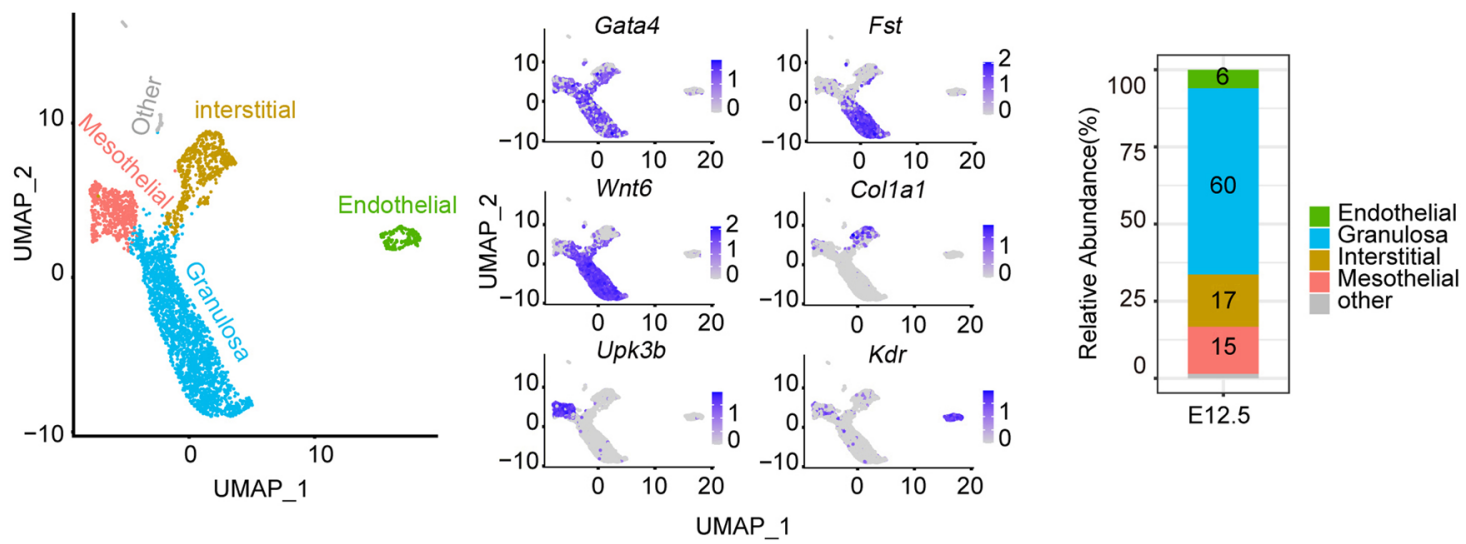

B
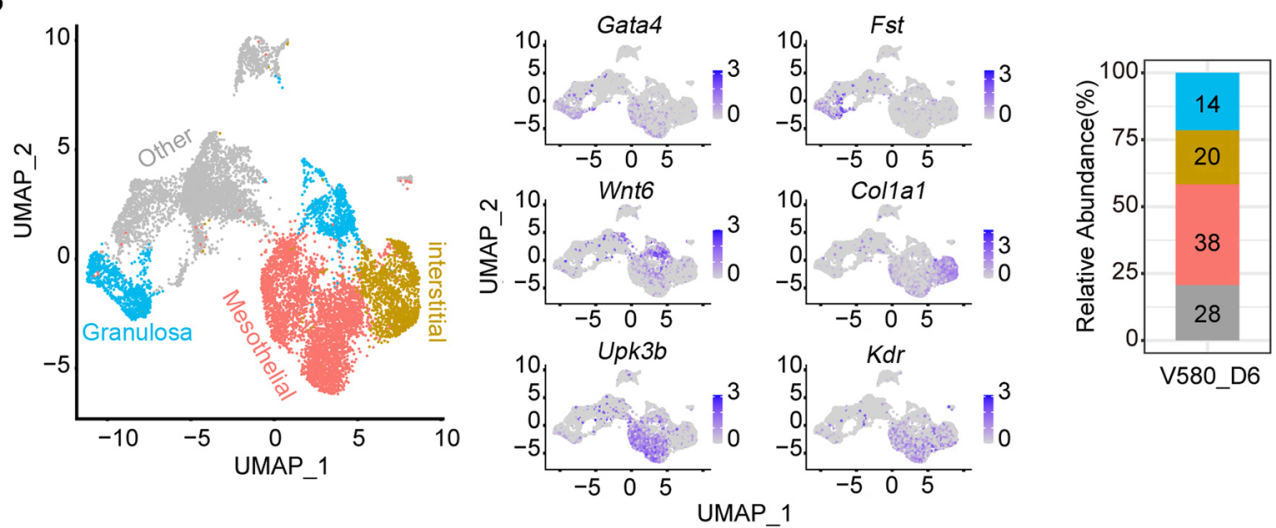

Granulosa

Interstitial

other

C
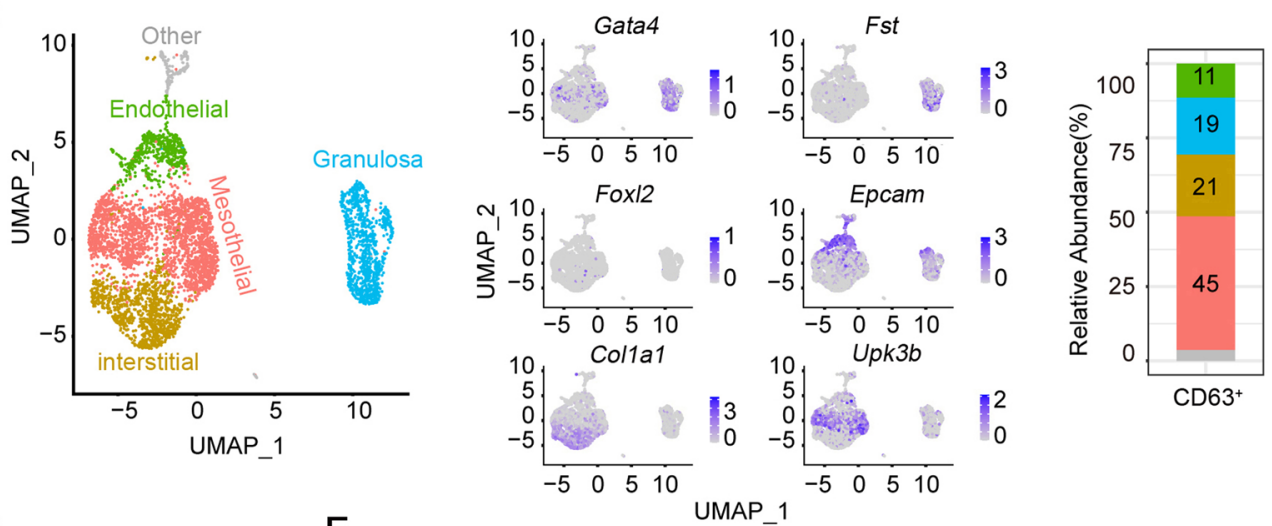

Endothelial

Granulosa

Mesothelial

other

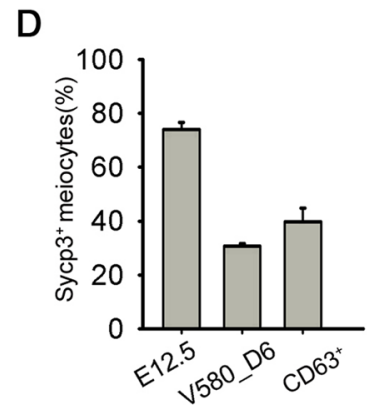

E

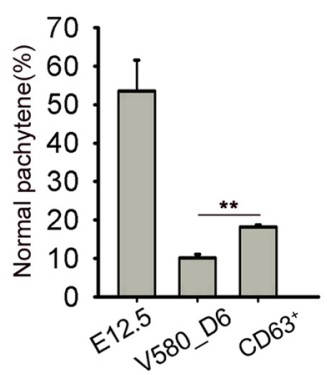

Fig. 5 (See legend on previous page.) 


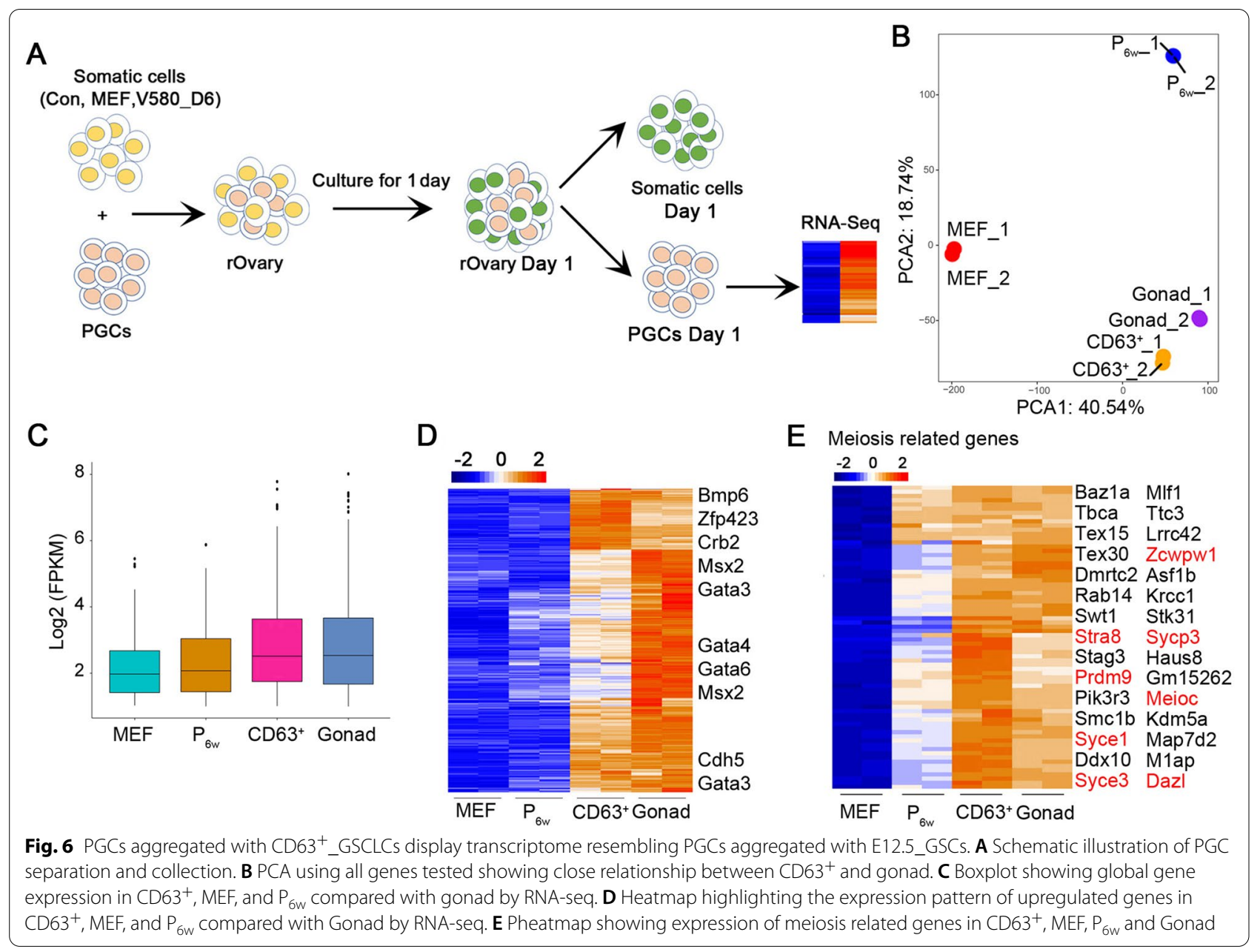

\section{Resemblance of $\mathrm{CD} 63^{+}$GSCLCs to E12.5_GSCs}

To determine the cell type present among V580_D6 GSCLCs, we performed $10 \times$ Genomics sequencing in triplicate. We compared the V580_D6 GSCLCs singlecell data with the previously published $10 \times$ sequencing data from E12.5 gonads (including germ cells and gonadal cells) [51]. Seurat was used to integrate the two datasets together for unified analysis. The mesothelial cells, endothelial cells, interstitial cells, and granulosa cells present in E12.5_GSCs were also among the V580_D6 GSCLCs. The proportions of endothelial cells and mesenchymal cells were similar to those in vivo, however, that of precursor granulosa cells was relatively low, accounting for only $14 \%$, compared with values of up to $60 \%$ in E12.5_GSCs. In addition, the proportion of unknown cell types was as high as $28 \%$ (Fig. 5A, B).

Following filtering based on CD63 expression $\left(\mathrm{CD}^{+} 3^{+}\right.$ GSCLCs), the GSCLCs population resembled E12.5 GSCs to a greater extent. The various cell types present in E12.5_GSCs were observed among CD63 ${ }^{+}$GSCLCs, including $45 \%$ mesothelial cells, $11 \%$ endothelial cells, $21 \%$ interstitial cells, and 19\% granulosa cells. The precursor granulosa cells increased from 14 to $19 \%$, and the proportion of unknown cell types was greatly reduced (Fig. 5C). Aggregates with $\mathrm{CD}^{+}{ }^{+}$GSCLCs $\left(\mathrm{CD} 63^{+}{ }_{-}\right.$aggregates) exhibited an increased proportion of PGCs initiating meiosis compared with V580_D6 aggregates (Fig. 5D). Proportion of PGCs in the pachytene stage was also significantly increased (Fig. 5E).

To further confirm that the $\mathrm{CD}^{+} 3^{+}$GSCLCs indeed shared E12.5_GSCs' function, we cultured the aggregates with gonad medium for 1 day, followed by separation using MACS columns and RNA-seq analysis of the PGCs transcriptome (Fig. 6A). PCA showed good repeatability and indicated that transcriptome of PGCs in Gonad_and $\mathrm{CD}^{+}{ }^{+}$- aggregates were similar (Fig. 6B). PGCs separated from Gonad_ and $\mathrm{CD} 3^{+}{ }_{-}$aggregates were readily distinguishable from $M E F_{-}$and $\mathrm{P}_{6 \mathrm{w}}$ aggregates based on global gene and specific marker expression (Fig. 6C, D). Numerous genes related to meiosis, including Dazl and 


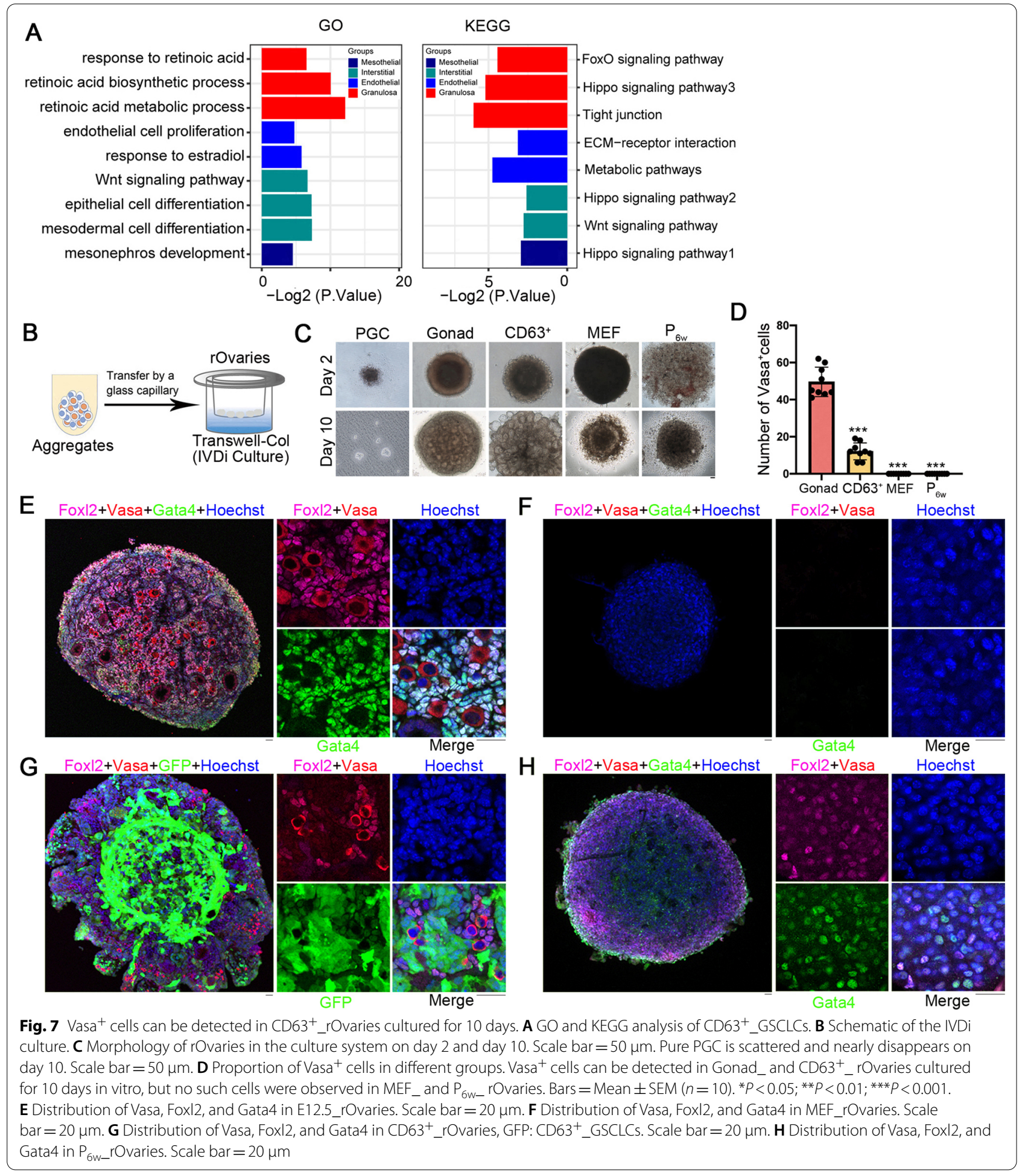

Stra8, were upregulated in PGCs isolated from $\mathrm{CD}^{+} 3^{+}$ and Gonad_aggregates (Fig. 6E).
Vasa-positive $\left(\mathrm{Vasa}^{+}\right)$cells in follicles of Gonad_ and $\mathrm{CD} 3^{+}$_rOvaries

GO and KEGG analysis of $\mathrm{CD}^{+} 3^{+}$GSCLCs revealed enrichment of retinoic acid related pathways and Hippo signaling in granulosa cell populations and Wnt-related 
pathway enrichment in interstitial cell populations. In the endothelial cell population, pathways related to endothelial cell proliferation and response to estradiol were enriched, whereas pathways related to mesonephric development and Hippo signaling were enriched in the mesothelial population (Fig. 7A). These pathways are also activated in the E12.5_GSCs population.

We attempted to reconstruct the oogenesis in vitro [33]. In this method (Fig. 7B), the cell population was first cultured in a low-adhesion 96-well plate for 2 days to form the aggregates, which were then transferred onto Transwell membranes, followed by culture under in vitro differentiation (IVDi) conditions. The folliclelike structures formed by $\mathrm{CD} 63^{+}{ }_{\text {rOVvaries was similar to }}$ that formed by the reaggregation of E12.5 gonads in vivo (Fig. 7C). Immunofluorescence microscopy revealed $\mathrm{Vasa}^{+}$cells in Gonad_and $\mathrm{CD} 3^{+}{ }_{\text {_ }}$ rOvaries cultured for 10 days in vitro, however, no such cells were observed in MEF or $\mathrm{P}_{6 \mathrm{w}-}$ rOvaries (Fig. $7 \mathrm{D}-\mathrm{H}$ ). In $\mathrm{CD} 3^{+}{ }_{-}$rOvaries cultured for 21 days, we detected $\mathrm{Vasa}^{+}$cells in later stage (Additional file 1: Fig. S8), further verifying that $\mathrm{CD}^{+}{ }^{+}$ GSCLCs indeed support the development of PGCs to form follicles. However, the efficiency was far lower than that of the normal developing follicles in rOvaries formed from E12.5_GSCs.

\section{Discussion}

We have been able to generate GSCLCs from ESCs via small-molecule treatment compounds. Specifically, combined treatment with Vc and AM580 induced GSCLCs from ESCs. Gata4 and Foxl2 expression gradually increased throughout the induction process, in line with the established Foxl2 upregulation during gonad development. Induction for short time is insufficient for achieving appropriate GSCLCs, yet prolonged induction tends to have more matured somatic cells. Through PCA and other analysis, we found that the transcriptome of V580_D6 GSCLCs resembled that of E12.5_GSCs and can support the initiation of meiosis in PGCs. Although V580_D6 GSCLCs did so to a relatively limited extent, control cells, MEF, and $\mathrm{P}_{6 \mathrm{w}}$ did not stimulate meiosis at all. In these groups, few PGCs exhibited Sycp3 expression, and Sycp1 was negligibly expressed. Moreover, V580_D6 GSCLCs partially exhibited E12.5_GSCs' function. Whereas cell sorting for CD63 revealed high similarity between E12.5_GSCs and CD63 ${ }^{+}$GSCLCs, which promote PGCs to undergo follicuologenesis containing Vasa $^{+}$cells, suggesting that $\mathrm{CD}^{+} 3^{+}$GSCLCs and E12.5 GSCs engage in similar functions.

Mature oocytes with full potency were generated through culturing ESCs and induced pluripotent stem cells. Moreover, pluripotent stem cell lines were re-derived from the oocytes that were generated in vitro, thereby recapitulating the full female germline cycle in a dish [33]. However, all of these culture systems require matched somatic cells, which are obtained from embryos at E12.5. Yoshino et al. reported that fetal gonadal somatic-like cells can be induced from ESCs [41]. Our data complemented the findings of Yoshino et al., demonstrating that fetal gonadal somatic-like cells can be induced by only two small molecules from ESCs, which function to promote meiosis induction and progression. Nevertheless, considerable research is required before the induced cells can be made to exert the same function of E12.5_GSCs.

\section{Conclusion}

In summary, our preliminary study demonstrates that fetal gonadal somatic-like cells can be induced by only two small molecules from ESCs, which function to promote meiosis induction and progression. We believe that our study adds contribution to the literature because the approach described will facilitate more indepth studies of oocyte production as well as research into the potential treatment of female infertility.

\section{Abbreviations}

ESCs: Embryonic stem cells; E12.5_GSCs: E12.5_gonadal somatic cells; PGCLCs: Primordial germ cell like cells; PGCs: Primordial germ cells; E12.5_GSCLCs: E12.5_GSC-like cells.

\section{Supplementary Information}

The online version contains supplementary material available at https://doi. org/10.1186/s13287-021-02672-4.

Additional file 1. Supplementary Figures and Legends. Supplementary Figures S1-S8. Supplementary Table S1.

\section{Acknowledgements}

We thank Kairang Jin, Feixiang Ge, Renpeng Guo, Peng Gong, Yu Yin and Peng $L i$, for their assistance with the experiments.

\section{Authors' contributions}

H.Y. conducted most of the experiments and wrote the manuscript; L.L.L. analyzed the data; C.L. and L.W. helped with part of the experiments and revised the manuscript. J.C., H.W., D.H., M.Z., C.L., Z.Z., H.L., Y.W., and X.Y. helped with part of the experiments. L.L. conceived the project, designed the experiments, and revised the manuscript. All authors read and approved the final manuscript.

\section{Funding}

This work was supported by the National Natural Science Foundation of China (32030033, 31430052)

\section{Availability of data and materials}

Relevant datasets have been uploaded as part of additional files. The accession numbers of RNA-seq data reported in this study is GEO: GSE181501. Data of E12.5_GSCs (10 × Genomics) were downloaded from NCBI [51]: GSE1 28553. The dataset used and/or analyzed during the current study are available from the corresponding author upon reasonable request. 


\section{Declarations}

\section{Ethics approval and consent to participate}

Not applicable.

\section{Consent for publication}

Not applicable.

\section{Competing interests}

The authors declare that they have no competing interests.

\section{Author details}

${ }^{1}$ State Key Laboratory of Medicinal Chemical Biology, Nankai University, Tianjin 300071, China. ${ }^{2}$ Department of Cell Biology and Genetics, College of Life Sciences; The Key Laboratory of Bioactive Materials Ministry of Education, Nankai University, Tianjin 300071, China. ${ }^{3}$ The Key Laboratory of Bioactive Materials Ministry of Education, College of Life Sciences, Nankai University, 94 Weijin Road, Tianjin 300071, China. ${ }^{4}$ Department of Cell Biology, College of Life Sciences, Tsinghua University, Beijing 100084, China. ${ }^{5}$ Department of Obstetrics and Gynecology, Center for Reproductive Medicine, Key Laboratory for Major Obstetric Diseases of Guangdong Province, The Third Affiliated Hospital of Guangzhou Medical University, Guangzhou, China. ${ }^{6}$ Guangzhou Women and Children's Medical Center, Guangzhou Medical University, Guangzhou 510655, China.

Received: 20 August 2021 Accepted: 2 December 2021 Published online: 20 December 2021

\section{References}

1. Appt $\mathrm{SE}$, et al. The effect of diet and cardiovascular risk on ovarian aging in cynomolgus monkeys (Macaca fascicularis). Menopause. 2010;17(4):741-8.

2. Luzzo KM, et al. High fat diet induced developmental defects in the mouse: oocyte meiotic aneuploidy and fetal growth retardation/brain defects. PLoS ONE. 2012;7(11):e49217.

3. Tarin JJ, Brines J, Cano A. Long-term effects of delayed parenthood. Hum Reprod. 1998;13(9):2371-6.

4. Appt SE, Ethun KF. Reproductive aging and risk for chronic disease: insights from studies of nonhuman primates. Maturitas. 2010;67(1):7-14.

5. Ballard K. Understanding risk: women's perceived risk of menopauserelated disease and the value they place on preventive hormone replacement therapy. Fam Pract. 2002;19(6):591-5.

6. Bleil ME, et al. Does accelerated reproductive aging underlie premenopausal risk for cardiovascular disease? Menopause. 2013;20(11):1139-46.

7. Clark IA, Atwood CS. Is TNF a link between aging-related reproductive endocrine dyscrasia and Alzheimer's disease? J Alzheimers Disease. 2011;27(4):691-9.

8. Matzuk MM, et al. Intercellular communication in the mammalian ovary: oocytes carry the conversation. Science. 2002;296(5576):2178-80.

9. Nilsson E, Skinner MK. Cellular interactions that control primordial follicle development and folliculogenesis. J Soc Gynecol Invest. 2001;8(1 Suppl Proceedings):S17-20.

10. Chen $\mathrm{M}$, et al. Abnormal meiosis initiation in germ cell caused by aberrant differentiation of gonad somatic cell. Oxid Med Cell Longev. 2019;2019:8030697.

11. Ford CE, et al. A functional "sex-reversed" oocyte in the mouse. Proc R Soc Lond B Biol Sci. 1975;190(1099):187-97.

12. Palmer SJ, Burgoyne PS. In situ analysis of fetal, prepuberal and adult $X X-X Y$ chimaeric mouse testes: Sertoli cells are predominantly, but not exclusively, XY. Development. 1991;112(1):265-8.

13. Edson MA, Nagaraja AK, Matzuk MM. The mammalian ovary from genesis to revelation. Endocr Rev. 2009;30(6):624-712.

14. McGee EA, Hsueh AJ. Initial and cyclic recruitment of ovarian follicles. Endocr Rev. 2000;21(2):200-14.

15. Saitou M, Miyauchi H. Gametogenesis from pluripotent stem cells. Cell Stem Cell. 2016;18(6):721-35.

16. McLaren A. Primordial germ cells in the mouse. Dev Biol. 2003:262(1):1-15.
17. De Felici M. The formation and migration of primordial germ cells in mouse and man. Results Probl Cell Differ. 2016:58:23-46.

18. Monget $\mathrm{P}$, et al. The ovarian reserve in mammals: a functional and evolutionary perspective. Mol Cell Endocrinol. 2012;356(1-2):2-12.

19. Findlay JK, et al. How is the number of primordial follicles in the ovarian reserve established? Biol Reprod. 2015;93(5):111.

20. Djahanbakhch O, Ezzati M, Zosmer A. Reproductive ageing in women. J Pathol. 2007;211(2):219-31.

21. Flurkey K, Harrison DE. Reproductive ageing: Of worms and women. Nature. 2010;468(7322):386-7.

22. Zhang $\mathrm{H}$, et al. Experimental evidence showing that no mitotically active female germline progenitors exist in postnatal mouse ovaries. Proc Natl Acad Sci USA. 2012;109(31):12580-5.

23. Yuan J, et al. No evidence for neo-oogenesis may link to ovarian senescence in adult monkey. Stem Cells. 2013;31(11):2538-50.

24. Hubner K, et al. Derivation of oocytes from mouse embryonic stem cells. Science. 2003;300(5623):1251-6.

25. Geijsen N, et al. Derivation of embryonic germ cells and male gametes from embryonic stem cells. Nature. 2004;427(6970):148-54

26. Toyooka Y, et al. Embryonic stem cells can form germ cells in vitro. Proc Natl Acad Sci USA. 2003;100(20):11457-62.

27. Hayashi $\mathrm{K}$, et al. Offspring from oocytes derived from in vitro primordial germ cell-like cells in mice. Science. 2012;338(6109):971-5.

28. Hayashi $\mathrm{K}$, et al. Reconstitution of the mouse germ cell specification pathway in culture by pluripotent stem cells. Cell. 2011;146(4):519-32.

29. Tian C, et al. Functional oocytes derived from granulosa cells. Cell Rep. 2019:29(13):4256-67.

30. Luisi S, et al. Hormone replacement therapy in menopause and in premature ovarian insufficiency. Minerva Ginecol. 2013:65(6):607-20.

31. Lacey JV Jr, et al. Menopausal hormone replacement therapy and risk of ovarian cancer. JAMA. 2002;288(3):334-41.

32. Terry MB, Tehranifar P. Hormone replacement therapy and breast cancer risk: more evidence for risk stratification? J Natl Cancer Inst. 2013;105(18):1342-3

33. Hikabe $\mathrm{O}$, et al. Reconstitution in vitro of the entire cycle of the mouse female germ line. Nature. 2016;539(7628):299-303.

34. McLaren A. Germ cells and germ cell sex. Philos Trans R Soc Lond B Bio Sci. 1995:350(1333):229-33.

35. McLaren A, Southee D. Entry of mouse embryonic germ cells into meiosis. Dev Biol. 1997:187(1):107-13.

36. Adams IR, McLaren A. Sexually dimorphic development of mouse primordial germ cells: switching from oogenesis to spermatogenesis. Development. 2002;129(5):1155-64.

37. Lei $L$, et al. Stage-specific germ-somatic cell interaction directs the primordial folliculogenesis in mouse fetal ovaries. J Cell Physiol. 2006;208(3):640-7.

38. Qing T, et al. Mature oocytes derived from purified mouse fetal germ cells. Hum Reprod. 2008;23(1):54-61.

39. Zeng $\mathrm{M}$, et al. Reconstitution of ovarian function following transplantation of primordial germ cells. Sci Rep. 2017;7(1):1427.

40. Hayashi K, Saitou M. Generation of eggs from mouse embryonic stem cells and induced pluripotent stem cells. Nat Protoc. 2013;8(8):1513-24.

41. Yoshino T, et al. Generation of ovarian follicles from mouse pluripotent stem cells. Science. 2021;373(6552):eabe0237.

42. Hou $P$, et al. Pluripotent stem cells induced from mouse somatic cells by small-molecule compounds. Science. 2013;341(6146):651-4.

43. Ichida JK, et al. A small-molecule inhibitor of tgf-Beta signaling replaces sox 2 in reprogramming by inducing nanog. Cell Stem Cell. 2009;5(5):491-503.

44. Huang J, et al. Efficient production of mice from embryonic stem cells injected into four- or eight-cell embryos by piezo micromanipulation. Stem Cells. 2008;26(7):1883-90.

45. Liu L, et al. Irregular telomeres impair meiotic synapsis and recombination in mice. Proc Natl Acad Sci USA. 2004;101(17):6496-501.

46. Kim D, Langmead B, Salzberg SL. HISAT: a fast spliced aligner with low memory requirements. Nat Methods. 2015;12(4):357-60.

47. Liao Y, Smyth GK, Shi W. featureCounts: an efficient general purpose program for assigning sequence reads to genomic features. Bioinformatics. 2014;30(7):923-30.

48. Love MI, Huber W, Anders S. Moderated estimation of fold change and dispersion for RNA-seq data with DESeq2. Genome Biol. 2014;15(12):550. 
49. Yu G, et al. clusterProfiler: an $\mathrm{R}$ package for comparing biological themes among gene clusters. OMICS. 2012;16(5):284-7.

50. Gribov A, et al. SEURAT: visual analytics for the integrated analysis of microarray data. BMC Med Genomics. 2010;3:21.

51. GeW, et al. Dissecting the initiation of female meiosis in the mouse at single-cell resolution. Cell Mol Life Sci. 2021;78(2):695-713.

52. Evans MJ, Kaufman MH. Establishment in culture of pluripotential cells from mouse embryos. Nature. 1981;292(5819):154-6.

53. Hunt PA, Hassold TJ. Human female meiosis: what makes a good egg go bad? Trends Genet. 2008;24(2):86-93.

54. Hamazaki N, et al. Reconstitution of the oocyte transcriptional network with transcription factors. Nature. 2021;589(7841):264-9.

55. Chassot AA, et al. RSPO1/beta-catenin signaling pathway regulates oogonia differentiation and entry into meiosis in the mouse fetal ovary. PLoS ONE. 2011;6(10):e25641.

56. Ottolenghi $\mathrm{C}$, et al. Loss of Wnt 4 and Foxl2 leads to female-to-male sex reversal extending to germ cells. Hum Mol Genet. 2007;16(23):2795-804.

57. Lavery R, et al. Testicular differentiation occurs in absence of R-spondin 1 and Sox9 in mouse sex reversals. PLoS Genet. 2012;8(12):e1003170.

58. Chassot AA, et al. Genetics of ovarian differentiation: Rspo1, a major player. Sex Dev. 2008;2(4-5):219-27.

\section{Publisher's Note}

Springer Nature remains neutral with regard to jurisdictional claims in published maps and institutional affiliations.

- fast, convenient online submission

- thorough peer review by experienced researchers in your field

- rapid publication on acceptance

- support for research data, including large and complex data types

- gold Open Access which fosters wider collaboration and increased citations

- maximum visibility for your research: over $100 \mathrm{M}$ website views per year

At BMC, research is always in progress.

Learn more biomedcentral.com/submissions 